\title{
Prevalence of Undiagnosed Type 2 Diabetes Mellitus and Its Associated Factors Among the Malaysian Population: The 2015 National Health and Morbidity Survey, Malaysia
}

\author{
Hasimah Ismail ${ }^{1}$, Mohd Azahadi Omar ${ }^{1}$, Thamil Arasu Saminathan ${ }^{1}$, Muhammad Fadhli Mohd Yusoff ${ }^{1}$, \\ Nor Azian Mohd Zaki ${ }^{1}$, Lim Kuang Kuay ${ }^{1}$ \& Tahir Aris ${ }^{1}$ \\ ${ }^{1}$ Institute for Public Health, Ministry of Health Malaysia, Kuala Lumpur, Malaysia \\ Correspondence: Thamil Arasu Saminathan, Institute for Public Health, National Institute of Health, Ministry of \\ Health Malaysia, Jalan Bangsar, 50590 Kuala Lumpur, Malaysia. Tel: 603-22-979-428. E-mail: \\ thamilarasu.s@moh.gov.my
}

Received: May 19, 2018 Accepted: June 24, 2018 Online Published: July 25, 2018

doi:10.5539/gjhs.v10n8p153 URL: https://doi.org/10.5539/gjhs.v10n8p153

\begin{abstract}
Background: The prevalence of diabetes has increased dramatically in the last decade. Compounding the problem are undiagnosed cases of type 2 diabetes mellitus. These respondents are those who do not know that they have the disease. Undiagnosed cases have substantial implications as they are at more risk to develope fatal complications. This study aims to determine the prevalence of undiagnosed T2DM and to identify its associated factors in Malaysia.
\end{abstract}

Methods: A nationwide cross-sectional study was conducted involving 19,935 respondents. Two-stage stratified sampling design was used to select a representative sample of the Malaysian adult population. Face-to-face interviews using structured, validated questionnaires were used to obtain data from the respondents. Respondents who claimed that they were not diagnosed with diabetes before were asked to undergo a finger-prick test.

Results: The overall prevalence of T2DM was $17.5 \%$ while the prevalence of undiagnosed T2DM was $9.2 \%$ $(\mathrm{n}=2103)$. Respondents aged 60 years old \& above had the highest percentage of undiagnosed T2DM at about $13.6 \%$, followed by those with no formal educational at $12.9 \%$, among Indians were $11.9 \%$, among female at $9.2 \%$, among non-working citizen at 9.8\%, widowed/divorced $(12.0 \%)$, smokers $(9.5 \%)$, obesity $(13.6 \%)$ and hypertensive (12.8\%). Multivariable analyses revealed that age group, ethnicity, education level, marital status, obesity and hypertensive were more likely to have undiagnosed T2DM.

Conclusion: This study showed a high prevalence of undiagnosed T2DM in Malaysia. Factors associated with undiagnosed diabetes mellitus were obesity, age, ethnicity, educational level and hypertension. Screening is essential among adults aged 30 to 60 year old to enable early intervention and prevent development of serious complications of this disease.

Keywords: prevalence of diabetes, undiagnosed, type 2 DM, risks factor, Malaysia

\section{Abbreviations}

T2DM: Type 2 diabetes mellitus; IDFA: International Diabetes Federation Atlas; LQ: Living quarters; EB: Enumeration blocks; BMI: Body Mass Index; IPAQ: International Physical Activity Questionnaire; MET: Metabolic equivalent of task; CI: Confidence interval; SD: Standard deviation.

\section{Background}

Type 2 diabetes mellitus (T2DM) has become a major public health problem both locally and globally. A report in 2006 described diabetes as an epidemic based on the dramatic increase in prevalence in the past 10 years (Steinbrook, 2006). Diabetes is increasingly diagnosed among adolescents and younger adults (Dabelea et al., 2009). Increase in obesity is one of the main factors thought to be driving the diabetes (Mainous, Diaz, \& Everett, 2007). As the prevalence of diabetes rises, there will be more young adults and adolescents with diabetes. Thus, it is crucial from a clinical and public health perspective to identify these high-risk populations (Mainous et al., 2007). In Malaysia, the National Health and Morbidity Survey (NHMS) in 2006 (Institute for Public Health, 2006) showed that the prevalence of T2DM was $11.6 \%$. This figure increased to $15.2 \%$ and $17.5 \%$ in NHMS 
2011(Institute for Public Health (IPH), 2011) and NHMS 2015 (Institute for Public Health, 2015) respectively.

The International Diabetes Federation Atlas (IDFA) in 2015 estimated 415 million people suffer from DM globally and the number is expected to increase to 642 million, with $45 \%$ of them remaining undiagnosed and thus unaware of their condition (IDFA, 2015). Whereas in Malaysia, the NHMS shows that undiagnosed diabetes among Malaysian population aged $\geq 30$ years was $1.8 \%$ in 1996 to 5.4\% in 2006 (Institute for Public Health, 2006), an alarming $200 \%$ increase in a decade. Undiagnosed diabetes has substantial public health implications because as these individuals remain untreated they are at risk of serious complications (Franse et al., 2001). Microvascular and macrovascular complications of untreated diabetes could cause morbidity and even mortality (Thévenod, 2008). The pathophysiology of T2DM are complex and interwoven and hence it is important to identify its risk factors. Socio-demographic factors were also found to be associated with prevalence of T2DM such as age (Wondemagegn et al., 2017), gender (Goto et al., 2015), higher BMI (Goto et al., 2015) and co-morbidities such as hypertension (Wondemagegn et al., 2017). This study aims to determine the prevalence of undiagnosed T2DM and to identify its associated factors in Malaysia.

\section{Methods}

This study used data from the National Health and Morbidity Survey (NHMS) 2015, a survey conducted by the Institute for Public Health, Ministry of Health Malaysia. NHMS 2015 employed a multi-stage stratified sampling design proportionate to the population size throughout all state in Malaysia, covering both urban and rural areas. The target population was residents of all non-institutional living quarters (LQ) in Malaysia for at least 2 weeks prior to data collection. Institutionalized populations such as those staying in hotel, hostels, hospitals etc. were excluded from the survey. Two-stage stratified sampling design was used to ensure national representativeness.

Geographical areas in Malaysia were divided into 75,000 Enumeration Blocks (EB). On average, each EB contains between 80 to 120 Living Quarters (LQs) with an average population of 500 to 600 people. The sampling frame was provided by Department of Statistic Malaysia. A total of 869 Enumeration Blocks (EB) were selected from the total EBs, of which 536 and 333 EBs were randomly selected from urban and rural areas respectively. Twelve LQs were randomly selected from each selected EB and all households within the selected LQs and all members in the households were surveyed (Institute for Public Health, 2015).

This study used structured questionnaires administered by trained interviewers. The data collection team conducted face-to-face interview using mobile devices with a system developed specially for the data collection. Completed questionnaires were sent to the data management team through the NHMS server in Institute of Public Health, whenever there was an internet connection. Quality control checks were performed (especially on the respondent ID, outliers or incorrect data). Modules in the structured questionnaires of the survey includes general household, socio-demographic, and specific health problems. Blood glucose level and blood pressure were also measured. The clinical anthropometric measurements we done by trained research assistants while the finger prick biochemistry tests were taken by qualified nurse. All measurements were taken by a member of the data collection team. A total of 10,428 LQs were sampled and all individuals aged 18 years and above were within the selected LQ were eligible to answer the diabetes module questionnaire. Informed consent was obtained from all the available and eligible respondents before the questionnaire was administered.

Measurement of fasting blood glucose was performed on finger-prick blood samples using the CardioChek portable blood test system, only on respondents who claimed to be not diabetic. Definition of "undiagnosed diabetes" for the purpose of this study is when the respondent was not diagnosed to have T2DM previously but had a fasting capillary blood glucose (FBG) of $\geq 6.1 \mathrm{mmol} / \mathrm{L}$ (World Health Organization. Dept. of Noncommunicable Disease Surveillance., 1999).

Respondents' systolic and diastolic blood pressure were measured using Omron digital automatic blood pressure monitors Model HEM-907 which had been validated and calibrated before being used in this study. Three readings were taken for both systolic and diastolic blood pressure, with a gap of 15 minutes between each reading and the average value of the second and third reading was recorded. Respondents were considered hypertensive if their average systolic blood pressure was $\geq 140 \mathrm{mmHg}$ and /or diastolic blood pressure $\geq 90 \mathrm{mmHg}$ or were self-reported hypertensives.

Weight of respondents were measured in kilograms using a digital weighing machine (TANITA HD-319) and height was measured in centimeters using Seca 206 Body meter. Body Mass Index (BMI) was calculated as weight divided by height squared. Respondents with BMI of $30.0 \mathrm{~kg} / \mathrm{m} 2$ or more were classified as obese ("WHO | Obesity: preventing and managing the global epidemic," 2015).

The respondents' physical activity level was assessed using the International Physical Activity Questionnaire 
(IPAQ) - short form. Respondents were classified as physically active if they achieved a minimum combination of vigorous-intensity, moderate-intensity and walking activities of 600 metabolic equivalent of task (MET)-minute/week (Institute for Public Health, 2015).

Smoking status of respondents who reported to have never smoked were reported as "non-smoker" and respondents who reported as still smoking during the interview were classified as "smoker".

\section{Statistical Analysis}

SPSS Version 20 were used to analyse the data. Categorical variables were presented as frequencies and percentages. Meanwhile, continuous variables were presented as means with $95 \%$ confidence interval (CI) and standard deviations (SD). Pearson's chi-square test was used in order to determine association between categorical variables.

Finally, multiple logistic regression analysis using a backward step wise method as performed to determine variable associated with undiagnosed diabetes when the effects of possible confounders were controlled. The selection of variable was based on the significant changes in the $-2 \log$ likelihood. The response variable was undiagnosed and the predictor variables included the analysis were age group, ethnic group, education level, marital status, occupational status physical activity level, obesity and blood pressure status. Adjusted odds ratios (AORs) and $95 \%$ confidence intervals (CIs) were estimated. Statistical significance was set at $\mathrm{P}$ value $<0.05$.

\section{Results}

\subsection{Socio-Demographics}

The total number of respondents for the diabetes questionnaire was 19,935 with the response rate of $91.1 \%$. Distribution of male and female respondents was nearly equal with slightly more females (52.4\%). By age, respondents aged 18 - 39 year old comprised $44.7 \%$ and urban residents $57.7 \%$ of the respondents. Malay respondents constituted the majority with $61.9 \%$, followed by Chinese $(16.0 \%)$ and Indian $(7.1 \%)$. More than $60.0 \%$ of respondents had up to either primary or secondary school education. About $70.0 \%$ respondents were married, while more than $60.0 \%$ were employed (Table 1 ).

Table 1. Socio-demographic characteristics of the respondents

\begin{tabular}{lll}
\hline Socio-demographic characteristic & $\mathbf{N}$ & $\mathbf{\%}$ \\
\hline Gender & & \\
Male & 9482 & 47.6 \\
$\quad$ Female & 10453 & 52.4 \\
\hline Age group(mean, sd) : 42.1, 15.99 & & \\
$\quad 8-39$ & 8906 & 44.7 \\
$40-59$ & 1924 & 36.3 \\
$60 \&$ above & 2174 & 19.0 \\
\hline Residence & & \\
Urban & 11504 & 57.7 \\
Rural & 8431 & 42.3 \\
\hline Ethnic group & & \\
Malay & 12345 & 61.9 \\
Chinese & 3193 & 16.0 \\
Indian & 1410 & 7.1 \\
Other indigenous & 1750 & 8.8 \\
Others & 1237 & 6.2 \\
\hline
\end{tabular}


Education level

$\begin{array}{lcc}\text { No formal education } & 1370 & 7.0 \\ \text { Primary school education } & 4781 & 24.3 \\ \text { Secondary school education } & 9147 & 46.4 \\ \text { Tertiary education } & 4397 & 22.3 \\ \text { Unclassified } & 216 & 1.1\end{array}$

Marital status

\begin{tabular}{cll} 
Single & 4191 & 21.0 \\
Married & 13805 & 69.3 \\
\hline Widow/widower/divorcee & 1939 & 9.7 \\
\hline Occupation status & & 60.9 \\
Working & 12139 & 39.1 \\
Not working & 7794 & \\
\hline
\end{tabular}

\subsection{Prevalence of Undiagnosed Diabetes Mellitus}

The prevalence of undiagnosed diabetes mellitus in this study was 9.2\% (95\% CI: 8.5, 9.9). There were significant differences by age group $(p<0.001)$, ethnic group $(p=0.014)$, educational level $(p<0.001)$, marital status $(p<0.001)$, occupation status $(\mathrm{p}=0.048)$, physical activity level $(\mathrm{p}=0.036)$, obesity status $(\mathrm{p}<0.001)$ and hypertensive status $(p<0.001)$. However, gender, residence, occupational status and smoking were not statistically significant factors in this study.

Table 2. Prevalence of undiagnosed diabetes mellitus by socio-demographic characteristics

\begin{tabular}{|c|c|c|}
\hline Socio-demographic characteristic & $\begin{array}{l}\text { Prevalence of undiagnosed diabetes mellitus } \\
\%(95 \% \mathrm{CI})\end{array}$ & p-value \\
\hline National & $9.2(8.5,9.9)$ & \\
\hline Gender & & 0.813 \\
\hline Male & $9.1(8.3,10.0)$ & \\
\hline Female & $9.2(8.4,10.2)$ & \\
\hline Age group & & $<0.001$ \\
\hline $18-39$ years & $7.0(6.3,7.9)$ & \\
\hline $40-59$ years & $11.7(10.5,12.9)$ & \\
\hline 60 years old and above & $12.3(11.0,13.9)$ & \\
\hline Residence & & 0.567 \\
\hline Urban & $9.1(8.2,10.0)$ & \\
\hline Rural & $9.5(8.5,10.6)$ & \\
\hline Ethnic group & & 0.014 \\
\hline Malays & $9.8(9.0,10.6)$ & \\
\hline Chinese & $7.7(6.4,9.4)$ & \\
\hline Indians & $11.9(9.5,15.0)$ & \\
\hline Other Bumiputra & $8.1(6.6,9.8)$ & \\
\hline Others & $8.6(6.7,11.1)$ & \\
\hline
\end{tabular}


Education level

No formal education

Primary school education

Secondary school education

Tertiary education

Marital status

Single

Married

Widow/widower/divorcee

Occupation status

Working

Not working

Smoking status

Smoker

Non-smoker

Physical activity

Active

Inactive

Obesity

Obese

Non-obese

Blood pressure status

Hypertensive

Normotensive
$<0.001$

$12.9(10.5,15.7)$

$11.1(9.8,12.6)$

$9.0(8.1,10.0)$

$7.1(6.1,8.3)$

$<0.001$

$6.4(5.5,7.6)$

$10.0(9.2,10.9)$

$12.0(10.1,14.2)$

0.048

$8.8(8.1,9.6)$

$9.8(8.9,10.8)$

0.496

$9.5(8.3,10.8)$

$9.1(8.3,9.8)$

$9.6(8.8,10.5)$

$8.4(7.6,9.3)$

$<0.001$

$13.6(12.2,15.2)$

$8.8(8.1,9.6)$

$<0.001$

$7.6(6.9,8.3)$

$12.8(11.8,14.0)$

\subsection{Factors Associated With Undiagnosed Diabetes Mellitus}

Multivariable analysis (multiple logistic regression) was performed for variables found significant in the univariate analysis (Table 3). Table 3 showed the adjusted odds ratios (aOR) of the factors, for undiagnosed diabetes mellitus. Significant associations were found for age group (40-59 years aOR 1.33 (95\% CI: 1.12,1.59) 60 year old and above aOR1.28 (95\% CI: 1.01,1.63), ethnic group (Malays aOR1.25 (95\% CI: 0.99,1.57) Indians aOR 1.47 (95\% 1.07, 2.01), Educational level (No formal education aOR 1.68 (95\% CI: 1.23, 2.27), Primary education aOR1.30 (95 CI: 1.05,1.62), Obese aOR1.42 (95\% CI: 1.22,1.64) and hypertensive status (aOR 1.33 (95\% CI: $1.15,1.53)$. No significant associations were found for occupational status, marital status and physical activity. 
Table 3. Factors associations with undiagnosed diabetes mellitus (using multiple logistic regression)

\begin{tabular}{|c|c|c|c|c|}
\hline & $\begin{array}{l}\text { OR } \\
(95 \% \mathrm{CI})\end{array}$ & p-value & $\begin{array}{l}\mathrm{aOR} \\
(95 \% \mathrm{CI})\end{array}$ & p-value \\
\hline \multicolumn{5}{|l|}{ Age group } \\
\hline $18-39$ & 1.00 & - & 1.00 & - \\
\hline $40-59$ & $1.75(1.51,2.03)$ & $<0.001$ & $1.33(1.12,1.59)$ & 0.001 \\
\hline 60 years old and above & $1.86(1.57,2.22)$ & $<0.001$ & $1.28(1.01,1.63)$ & $<0.040$ \\
\hline \multicolumn{5}{|l|}{ Ethnic group } \\
\hline Chinese & 1.00 & - & 1.00 & - \\
\hline Malays & $1.30(1.04,1.62)$ & 0.021 & $1.25(0.99,1.57)$ & 0.057 \\
\hline Indians & $1.62(1.19,2.20)$ & 0.002 & $1.47(1.07,2.01)$ & 0.017 \\
\hline Other Bumiputra & $1.04(0.77,1.41)$ & 0.780 & $0.90(0.66,1.23)$ & 0.521 \\
\hline Others & $1.12(0.80,1.57)$ & 0.503 & $1.06(0.75,1.50)$ & 0.758 \\
\hline \multicolumn{5}{|l|}{ Education level } \\
\hline No formal education & $1.92(1.45,2.55)$ & $<0.001$ & $1.68(1.23,2.29)$ & 0.001 \\
\hline Primary education & $1.63(1.33,1.99)$ & $<0.001$ & $1.30(1.05,1.62)$ & 0.016 \\
\hline Secondary education & $1.29(1.08,1.54)$ & $<0.001$ & $1.15(0.96,1.38)$ & 0.136 \\
\hline Tertiary education & 1.00 & - & 1.00 & - \\
\hline \multicolumn{5}{|l|}{ Marital status } \\
\hline Single & 1.00 & - & 1.00 & - \\
\hline Married & $1.62(1.34,1.95)$ & $<0.001$ & $1.21(0.96,1.51)$ & 0.099 \\
\hline Widow/widower/divorced & $1.98(1.54,2.55)$ & $<0.001$ & $1.23(0.91,1.67)$ & 0.172 \\
\hline \multicolumn{5}{|l|}{ Occupation status } \\
\hline Working & 1.00 & - & 1.00 & - \\
\hline Not working & $1.13(1.001,1.27)$ & $<0.001$ & $0.97(0.85,1.12)$ & 0.705 \\
\hline \multicolumn{5}{|l|}{ Physical activity level } \\
\hline Active & 1.00 & - & 1.00 & - \\
\hline Inactive & $0.86(0.756,0.99)$ & 0.036 & $0.87(0.76,1.01)$ & 0.070 \\
\hline \multicolumn{5}{|l|}{ Obesity } \\
\hline Obese & $1.63(1.42,1.88)$ & $<0.001$ & $1.42(1.22,1.64)$ & $<0.001$ \\
\hline Non-obese & 1.00 & & 1.00 & \\
\hline \multicolumn{5}{|l|}{ Blood pressure status } \\
\hline Hypertensive & $1.80(1.60,2.03)$ & $<0.001$ & $1.33(1.15,1.53)$ & $<0.001$ \\
\hline Normotensive & 1.00 & & 1.00 & \\
\hline
\end{tabular}

Notes. ${ }^{*} \mathrm{p}<0.05$ was considered statistical significant.

\section{Discussion}

Our study shows that nearly 1 in 10 Malaysians have undiagnosed DM. Although the prevalence of $9.2 \%$ is lower compared to some Southeast Asian countries; $11.1 \%$ in Tamil Nadu (Subramani, Devi, \& Shankar, 2014) and 11.1\% in Singapore (Huang et al., 2015) but it is nonetheless significantly higher compared to other countries like Canada (2.2\%) (Flores-Le Roux et al., 2011) and the United Kingdom (2.0\%) (Moody, Cowley, Ng Fat, \& Mindell, 2016). These undiagnosed DM in Malaysia could be due to lack of awareness of the necessity of health screening at an earlier age and of early diabetes symptoms. Furthermore, patient overload in public primary health care centers 
pose difficulties and hinder Malaysians from seeking diabetes screening (Letchuman et al., 2006). Factors such as population growth, population aging, increasing urbanization and increasing prevalence of obesity and physical inactivity could also play a role, especially in developing and developed countries. For example, in the United States of America, the Diabetes Statistics Report of 2014 stated that a total of 29.1 million (9.3\%) of its population had diabetes but 8.1 million (27.8\%) of them were undiagnosed (Centers for Disease Control and Prevention, 2014).

Based on Table 2, the prevalence of undiagnosed DM increases with age as it was higher among those aged 60 years and above $(12.3 \%)$. This is probably due to increasing tendency to exercise less or being physical inactive, loss of muscle mass and gaining weight with age. It has been established that the more abundant the fatty tissue in the body, the more resistant are the cells to insulin (Wondemagegn et al., 2017). This finding is similar to findings from Azimi-Nezhad et al. in Iran (R \& M J, 2008) which showed that further age-related glucose intolerance is related to decreased insulin sensitivity and decreased $\beta$ - cell function(Shih, Tseng, \& Article, 2009).

There seems to be an association between undiagnosed DM and ethnicity in Malaysia. This study shows a high prevalence of undiagnosed DM among Malaysian Indians compared to Malays and Malaysian Chinese. Respondents of Indian descent had the highest prevalence of undiagnosed DM not only in the recent NHMS 2015 but also in NHMS 2011 and 2006. Our study shows that Indians were 1.47 times more likely to have undiagnosed DM compared to the others ethnic group. In the Malaysian context, this may be attributed to differences in the food consumption pattern, dietary behavior, lifestyle and genetic susceptibility between the three major races in Malaysia. This study also found lower prevalence of undiagnosed DM among Malaysians of Chinese descent. This situation is probably due to many Chinese living in urban areas that have adequate health facilities and amenities as well as transportation system that can facilitate in early detection of diabetes mellitus among them.

The results in table 2 show that the prevalence of undiagnosed DM among widow/widower/ divorced and married individuals are significantly higher compared to those who are unmarried. This finding is consistent with the NHMS 2015 survey. Married individuals are 1.21 times more likely to have undiagnosed DM compared to single individuals. Some finding suggest that time constrain when managing careers and family life among married couples may cause lack of opportunity and awareness for prevention practices (Golden et al., 2012). However, other study have suggested that single, divorced and widowed statuses increase the risk of developing DM (Poljičanin, T., Šekerija, M., Boras, Kolarić, Vuletić, \& Metelko, 2012).

In terms of education status, higher prevalence was observed in those without formal education, followed by those with primary education. There was a statistical significant association between education status and undiagnosed DM. Low education status may be associated with less awareness and less opportunity for prevention/control, and vice versa, for those with higher education status. However, the present study differs from other studies which found a lack of association, for example Muyer et al., 2012 and Signorello et al., 2007 in USA. Further study is needed to confirm the association between education and DM.

The results showed higher prevalence of undiagnosed DM among obese individuals. This study revealed that obese people were 1.42 times more likely to have undiagnosed DM. Studies by NHMS 2011(Institute for Public Health, 2015), and Nyamdorj et al., 2010 in Finland also reported a significant positive association between obesity or high BMI status with undiagnosed DM. It has been postulated that large abdominal fat stores affect insulin metabolism by releasing free fatty acids (Bennett, Guo, \& Dharmage, 2007). In addition, fat cells secrete signaling factors Interlukein-6 (IL-6) and tumor necrosis factor- $\alpha$ (TNF- $\alpha$ ) which is involved in the development of insulin resistance(Bennett et al., 2007).

This study revealed that respondents who had hypertension are 1.33 times more likely to have undiagnosed DM. Similar findings were reported in a Kenyan study by Meme, Amwayi, Nganga, \& Buregyeya, 2015 and in Ethiopia study by Amsalu T W, Habtamu M B et al 2017. This association could be partially due to physiological traits: this mean that the effects of one disease increases the likelihood for developing the other disease. In addition, the two are more likely to occur together simply because they have important shared risk factors. Screening for DM should also be targeted at hypertensive patients in Malaysia as study had shown that lowering blood pressure can reduce the incidence of clinically-detected diabetes ("Screening for Type 2 Diabetes Mellitus in Adults: U.S. Preventive Services Task Force Recommendation Statement," 2008).

This study has some limitations. Although the NHMS 2015 was a national study that provided representative data, there were only a limited number of variables on the possible risk factors for undiagnosed DM that could be included in the analysis. Also, because there were few studies pertaining to undiagnosed DM, there were difficulties when it comes comparing results. 


\section{Conclusion}

Undiagnosed T2DM among Malaysians were significant in 2015. Results from this study show that significant associated factors of undiagnosed T2DM are age, ethnic group, education level, marital status, physical activity level, obesity and blood pressure status. It is alarming to know that a large proportion of the community have diabetes mellitus but were unaware of it. Therefore, increasing public awareness of the importance of early diabetic screening is crucial especially among adults aged 30 years and above, and among high risk groups to prevent more serious complications and reduce the burden of this disease.

\section{Declarations}

\section{Ethics Approval and Consent to Participate}

Ethical approval was obtained from the Medical Research and Ethics Committee of the Ministry of Health Malaysia.

\section{Consent for Publication}

Not applicable.

\section{Availability of Data and Materials}

\section{Funding}

Not applicable.

\section{Authors' Contributions}

HI, MAO and TAS contributed to management and acquisition of the data, conducted the analysis and interpretation of data and drafted the manuscript. MFM, NAMZ, LKK and TA contributed drafted the manuscript and critically reviewing the content. All authors revised and approved the final manuscript.

\section{Acknowledgements}

The authors express their gratitude to the Director-General of Health Malaysia, for his kind support and permission to publish this paper, the Director of the Institute for Public Health for his support.

\section{Competing Interests Statement}

The authors declare that they have no competing interests.

\section{References}

Bennett, C. M., Guo, M., \& Dharmage, S. C. (2007). $\mathrm{HbA}_{1 \mathrm{c}}$ as a screening tool for detection of Type 2 diabetes: a systematic review. Diabetic Medicine, 24(4), 333-343. https://doi.org/10.1111/j.1464-5491.2007.02106.x

Centers for Disease Control and Prevention. (2014). Estimates of Diabetes and Its Burden in the United States Fast Facts on Diabetes Number with diabetes Total By sex National Diabetes Statistics Report, 2014. Retrieved from http://diabetes.niddk.nih.gov/dm/pubs/comparingtests/index.aspx

Dabelea, D., DeGroat, J., Sorrelman, C., Glass, M., Percy, C. A., Avery, C., ... SEARCH for Diabetes in Youth Study Group. (2009). Diabetes in Navajo Youth: Prevalence, incidence, and clinical characteristics: the SEARCH for Diabetes in Youth Study. Diabetes Care, 32(Supplement_2), S141-S147. https://doi.org/10.2337/dc09-S206

Flores-Le Roux, J. A., Comin, J., Pedro-Botet, J., Benaiges, D., Puig-de Dou, J., Chillarón, J. J., ... Cano-Perez, J. F. (2011). Seven-year mortality in heart failure patients with undiagnosed diabetes: an observational study. Cardiovascular Diabetology, 10(1), 39. https://doi.org/10.1186/1475-2840-10-39

Franse, L. V, Di Bari, M., Shorr, R. I., Resnick, H. E., van Eijk, J. T., Bauer, D. C., ... Health, Aging, and Body Composition Study Group. (2001). Type 2 diabetes in older well-functioning people: who is undiagnosed? Data from the Health, Aging, and Body Composition study. Diabetes Care, 24(12), 2065-2070. https://doi.org/10.2337/DIACARE.24.12.2065

Golden, S. H., Brown, A., Cauley, J. A., Chin, M. H., Gary-Webb, T. L., Kim, C., ... Anton, B. (2012). Health Disparities in Endocrine Disorders: Biological, Clinical, and Nonclinical Factors-An Endocrine Society Scientific Statement. The Journal of Clinical Endocrinology \& Metabolism, 97(9), E1579-E1639. https://doi.org/10.1210/jc.2012-2043

Goto, M., Goto, A., Ikeda, N., Noda, H., Shibuya, K., \& Noda, M. (2015). Factors Associated with Untreated Diabetes: Analysis of Data from 20,496 Participants in the Japanese National Health and Nutrition Survey. 
PLOS ONE, 10(3), e0118749. https://doi.org/10.1371/journal.pone.0118749

Huang, O. S., Tay, W. T., Ong, P. G., Sabanayagam, C., Cheng, C.-Y., Tan, G. S., ... Wong, T. Y. (2015). Prevalence and determinants of undiagnosed diabetic retinopathy and vision-threatening retinopathy in a multiethnic Asian cohort: the Singapore Epidemiology of Eye Diseases (SEED) study. The British Journal of Ophthalmology, 99(12), 1614-1621. https://doi.org/10.1136/bjophthalmol-2014-306492

Institute for Public Health [IPH]. (2006). National Health and Morbidity Survey 2006 (NHMS 2006). Retrieved from http://iku.moh.gov.my/images/IKU/Document/REPORT/2006/DiabetesMellitus.pdf

Institute for Public Health [IPH]. (2011). National Health And Morbidity Survey 2011 Volume Ii Non-Communicable Diseases. Retrieved from http:/iku.moh.gov.my/images/IKU/Document/ REPORT/NHMS2011-VolumeII.pdf

Institute for Public Health [IPH]. (2015). National Health And Morbidity Survey 2015 Ministry Of Health Malaysia, 2. Retrieved from http://iku.moh.gov.my/images/IKU/Document/REPORT/nhmsreport 2015vol2.pdf

Letchuman, G. R., Wan Nazaimoon, W. M., Wan Mohamad, W. B., Chandran, L. R., Tee, G. H., Jamaiyah, H., ... Ahmad Faudzi, Y. (n.d.). Prevalence of Diabetes in the Malaysian National Health Morbidity Survey III 2006. Retrieved from http://www.e-mjm.org/2010/v65n3/Diabetes.pdf

Mainous, A. G., Diaz, V. A., \& Everett, C. J. (2007). Assessing risk for development of diabetes in young adults. Annals of Family Medicine, 5(5), 425-429. https://doi.org/10.1370/afm.705

Meme, N., Amwayi, S., Nganga, Z., \& Buregyeya, E. (2015). Prevalence of undiagnosed diabetes and pre-diabetes among hypertensive patients attending Kiambu district Hospital, Kenya: a cross-sectional study. Pan African Medical Journal, 22. https://doi.org/10.11604/pamj.2015.22.286.7395

Moody, A., Cowley, G., Ng Fat, L., \& Mindell, J. S. (2016). Social inequalities in prevalence of diagnosed and undiagnosed diabetes and impaired glucose regulation in participants in the Health Surveys for England series. BMJ Open, 6(2), e010155. https://doi.org/10.1136/bmjopen-2015-010155

Muyer, M. T., Muls, E., Mapatano, M. A., Makulo, J.-R., Mvitu, M., Kimenyembo, W., ... Buntinx, F. (2012). Diabetes and intermediate hyperglycaemia in Kisantu, DR Congo: a cross-sectional prevalence study. $B M J$ Open, 2(6), e001911. https://doi.org/10.1136/bmjopen-2012-001911

Nyamdorj, R., Pitkäniemi, J., Tuomilehto, J., Hammar, N., Stehouwer, C. D. A., Lam, T. H., ... Qiao, Q. (2010). Ethnic comparison of the association of undiagnosed diabetes with obesity. International Journal of Obesity, 34(2), 332-339. https://doi.org/10.1038/ijo.2009.225

Poljičanin, T., Šekerija, M., Boras, J., Kolarić, B., Vuletić, S., \& Metelko, Ž. (2012). Cumulative incidence of self-reported diabetes in Croatian adult population in relation to socioeconomic status and lifestyle habits. Collegium Antropologicum, 36 supplem(1), 41-46. Retrieved from https://hrcak.srce.hr/75587?lang=en

R, P. M., \& M J, P. S. (2008). Prevalence of type 2 diabetes mellitus in Iran and its relationship with gender, urbanisation, education, marital status and occupation. Original Article Singapore Med J, 49(7), 571. Retrieved from http://smj.sma.org.sg/4907/4907a9.pdf

Screening for Type 2 Diabetes Mellitus in Adults: U.S. Preventive Services Task Force Recommendation $\begin{array}{llllll}\text { Statement. (2008). Annals of Internal } & \text { Medicine, } & \text { 148(11), } & 846 .\end{array}$ https://doi.org/10.7326/0003-4819-148-11-200806030-00007

Shih, S.-R., Tseng, C.-H. (2009). The Effects of Aging on Glucose Metabolism The Effects of Aging on Glucose Metabolism. Taiwan Geriatrics \& Gerontology, 4(1), 27-38. Retrieved from http://www.tagg.org.tw/DOWN/雜誌/4-1期/0-4-1-綜論3-施翔蓉.pdf

Signorello, L. B., Schlundt, D. G., Cohen, S. S., Steinwandel, M. D., Buchowski, M. S., McLaughlin, J. K., ... Blot, W. J. (2007). Comparing diabetes prevalence between African Americans and Whites of similar socioeconomic status. American Journal of Public Health, 97(12), 2260-2267. https://doi.org/10.2105/AJPH.2006.094482

Steinbrook, R. (2006). Facing the Diabetes Epidemic - Mandatory Reporting of Glycosylated Hemoglobin Values in New York City. New England Journal of Medicine, 354(6), 545-548. https://doi.org/10.1056/NEJMp068008

Subramani, R., Devi, U., \& Shankar, U. (2014). Prevalence of Undiagnosed Type 2 Diabetes and its Associated 
Risk Factors in Rural Population of Tamil Nadu. World Journal of Medical Sciences, 11(2), 222-227. https://doi.org/10.5829/idosi.wjms.2014.11.2.84252

Thévenod, F. (2008). Pathophysiology of Diabetes Mellitus Type 2: Roles of Obesity, Insulin Resistance and \&amp;Bgr;-Cell Dysfunction. In Diabetes and Cancer (Vol. 19, pp. 1-18). Basel: KARGER. https://doi.org/10.1159/000152019

Wondemagegn, A. T., Bizuayehu, H. M., Abie, D. D., Ayalneh, G. M., Tiruye, T. Y., \& Tessema, M. T. (2017). Undiagnosed Diabetes Mellitus and Related Factors in East Gojjam (NW Ethiopia) in 2016: A Community-Based Study. Journal of Public Health Research, 6(1), 834. https://doi.org/10.4081/jphr.2017.834

World Health Organization [WHO]. (2015). Obesity: preventing and managing the global epidemic.

World Health Organization [WHO]. (1999). Definition, diagnosis and classification of diabetes mellitus and its complications: Report of a WHO consultation. Part 1, Diagnosis and classification of diabetes mellitus. Department of Noncommunicable Disease Surveillance. Retrieved from http://www.who.int/iris/handle/10665/66040

\section{Copyrights}

Copyright for this article is retained by the author(s), with first publication rights granted to the journal.

This is an open-access article distributed under the terms and conditions of the Creative Commons Attribution license (http://creativecommons.org/licenses/by/4.0/). 